\title{
Shaping ability of thermomechanically treated files in simulated S-shaped root canals
}

\author{
Nessrin A. Taha ${ }^{1 *}$, Ghada A. Maghaireh ${ }^{1}$, Dyana El Sadek ${ }^{1}$, Rafat Bagheri ${ }^{2}$, Mohammad Al-Omari ${ }^{1}$ \\ ${ }^{1}$ Department of Conservative Dentistry, Jordan University of Science and Technology, Irbid, Jordan \\ ${ }^{2}$ Biomaterial Research Center, School of Dentistry, Shiraz University of Medical Sciences, Shiraz, Iran \\ Email: ${ }^{*}$ n.taha@just.edu.jo
}

Received 2 August 2013; revised 21 October 2013; accepted 28 October 2013

Copyright (C) 2013 Nessrin A. Taha et al. This is an open access article distributed under the Creative Commons Attribution License, which permits unrestricted use, distribution, and reproduction in any medium, provided the original work is properly cited.

\begin{abstract}
Aim: the aim of this study was to investigate the shaping ability of thermomechanically treated files manufactured by twisting (Twisted files) and compare it to conventional rotary system (K3, Sybron Endo, Orange, CA) in S-shaped canals, including formation of ledges, zipping, elbow, outer widening, danger zone, perforation and file deformation. Materials \& Methods: Forty S-Shaped canals in resin blocks were randomly divided into 2 groups of 20 each. Pre-instrumentation images of the canals were taken via a digital camera and superimposed on images taken after preparation with $\mathrm{TF}$ and $\mathrm{K} 3$ systems to apical size of 25/06 and 30/06. Canal aberrations were measured from the superimposed image at five levels using AutoCAD system. Fisher exact test and Mann Whitney test were used for analysis of the data. Results: the incidence of zipping, elbow and apical transportation was significantly lower in the $T F$ group $(P=0.04)$. Generally the incidence of aberration increased when the apical size increased to 30/0.06 regardless of the file system. Significant file deformation was evident in the TF after single use ( $P$ $<0.001$ ). Conclusion: Under the conditions of this study, TF manufactured by new technique performed better than K3 systems when used up to size 25/06 in simulated S-shaped canals. Clinical significance: The flexibility of thermomechanically treated files is beneficial in canals with multiple curvatures; however, attention should be paid to the instrument taper and final apical size of the preparation.
\end{abstract}

Keywords: S-Shaped Canal; Twisted Files; K3; Canal Aberration

*Corresponding author.

\section{INTRODUCTION}

The ultimate biological aim of root canal treatment is to treat or prevent apical periodontitis. The biological objectives of chemomechanical preparation are to remove all infected tissues from the root canal space and confine instrumentation within the root canal without forcing necrotic debris beyond the apical foramen [1]. The mechanical objectives of cleaning and shaping are to facilitate delivery of antimicrobial irrigants and create resistance form against which a root filling can be compacted, maintain the path of original canal and consider the multiple geometric planes and curves more than the roots that house them. Moreover, the apical foramen should remain in its original position, hence canal transportation may damage the apical foramen and create foraminal zip or tear which was found to have a negative effect on the apical seal especially when curved root canals are obturated with cold lateral compaction technique [2].

Numerous studies have shown the ability of nickel titanium (NiTi) rotary instruments to effectively produce a well tapered root canal with minimal risk of transporting the original canal [3-6]. Most NiTi systems are manufactured by grinding method which may result in microcracks that can become the focus of fracture if the file is exposed to excess torsion and cyclic fatigue. Therefore, a new manufacturing method by twisting has been introduced to overcome limitations of the grinding method by increasing the hardness, reducing torsional failure and cyclic fatigue [7] which subsequently maximizes file flexibility and improves its shaping ability $[8,9]$.

Canal anatomy including S-shaped curvature can pose serious challenges to the operator. The S-shape canal is common in maxillary premolars, lateral incisors and canines and mandibular molars. These canals have two curves, with the apical curve being the most difficult to negotiate. The chances of creating a strip perforation in this area are high and are dependent on the degree of 
apical curvature. Preflaring of the coronal third has been suggested to reduce the angle of curvature and to facilitate negotiation of the apical curve. [10] The use of $\mathrm{S}$-shaped resin blocks is relatively common in studies evaluating shaping abilities including apical zipping and ledging; [11-13] hence they offer the advantages of canal shape standardization and the ability to visualize intracanal accidents. The aim of this study was to evaluate the shaping ability of Twisted files (TF; SybronEndo, Orange, CA) manufactured from R-phase alloy using a twisting method and compare it to the $\mathrm{K} 3$ rotary file system (SybronEndo, Orange, CA) manufactured by the conventional grinding method in simulated S-shaped root canals after two apical preparation sizes.

\section{MATERIALS AND METHODS}

\subsection{Simulated Canal Preparation}

Fourty simulated S-shaped root canals in clear resin blocks (Endo training Bloc-S; Dentsply Mallifer, balligues, Switzerland), with a $30^{\circ}$ coronal curvature, $20^{\circ}$ apical curvature and $16 \mathrm{~mm}$ canal length were randomly assigned into 2 groups, the TF group and the $\mathrm{K} 3$ group. Two orientation grooves were drilled in each block to facilitate superimposition of the images.

A preoperative image of each simulated resin block was recorded by a digital camera (Nikon digital camera D70s, Japan) and macro lens (Sigma $105 \mathrm{~mm}$ macro, Japan). In order to take standardized and reproducible pictures, a custom made camera stand was used and camera was placed on a fixed distance $(14.5 \mathrm{~mm})$ from the block which was placed in a custom made template. Each canal was injected with red ink before taking the image, and the image was saved as JPEG file on a linked computer [14].

A glyde path was then established in the simulated canals to the full working length $(16 \mathrm{~mm})$ with sizes 8 , 10, 15 stainless steel K-files, canals were irrigated with $1 \mathrm{ml}$ distilled water using 27 gauge needles. Subsequently in the TF group canals were prepared according to the manufacturer's recommendations using crown down technique with rotary handpiece (DentaPort ZX J. Morita MFG Corp., Tokyo, Japan) at $500 \mathrm{rpm}$ without torque (www.tfwithrphase.com-TF-brochure). The shaping procedure was started with size $25 / 0.08$ in the coronal one third of the canal, then $25 / 0.06$ inserted to resistance. Finally the following 3 files 25/0.04, 25/0.06, 30/0.06 were used for apical preparation at full working length.

In the K3 group canals were prepared with K3 rotary system with constant speed of $250 \mathrm{rpm}$ at torque 2 using a crown down approach. The shaping procedure was started with size 25/0.12 in the orifice then size 25/0.10 and $25 / 0.08$ in the coronal one third, followed by size
25/0.06 taken to $2 \mathrm{~mm}$ short of the length and finally the following 3 files were used for apical preparation at full working length 25/0.04, 25/0.02, 25/0.04, 25/0.06 and $30 / 0.06$. Each canal was shaped with new instruments lubricated with Glyde-Prep (Dentsply Maillefer), patency was confirmed with size $10 \mathrm{~K}$-file, and canals were irrigated with $1 \mathrm{ml}$ distilled water after each instrument. All used files were evaluated for deformation.

\subsection{Assessment of Canal Preparation}

Two postoperative images were taken; one after preparation with size 25/0.06 and the second after preparation with size 30/0.06. The preoperative and post operative images were superimposed using image Adobe Photoshop (Adobe Systems Inc, San Jose, CA).

The final composed images were imported into Autocad 2007 and were blindly assessed by two experienced clinicians at five levels [15]. (Figure 1):

Position 1: half way of the straight part of canals (7 $\mathrm{mm}$ from orifice).

Position 2: beginning of the first curve. This was determined as the point where the canal starts to deviate from the long axis of the straight part of the canal at first curve.

Position 3: apex of the first curve. This was deter

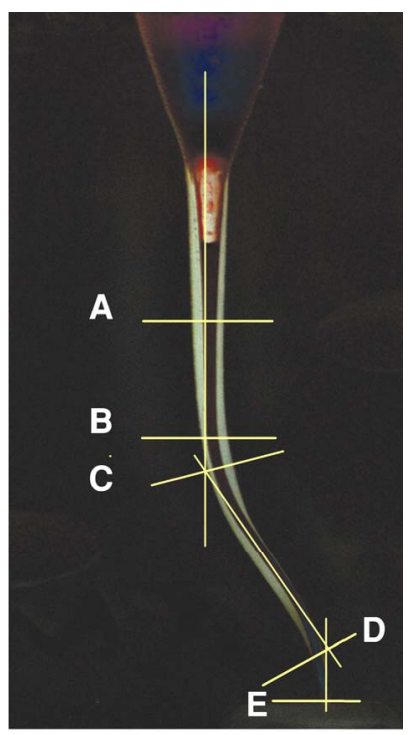

Figure 1. Superimposed image show the five assessment levels in the S shape canal: (A) Position 1: Half way of straight part of canals, (B) Position 2: Beginning of the first curve. (C) Position 3: Apex of first curve. (D) Position 4: Apex of second curve. (E) Position 5: Apical end, this represent the end point of the preparation. 
mined by intersection of two lines one drawn along the outer border of straight part of canal and the second drawn along the outer border of a line extending between the two curves.

Position 4: apex of second curve. This was determined by the intersection of two lines one drawn along the outer border of a line extending between the two curves and the second drawn along the outer border of the apical aspect of the canal.

Position 5: apical end which represents the end point of the preparation.

Each canal was assessed for the presence of canal aberrations including, zip, elbow, ledges, perforation, danger zone and outer widening according to al-Omari et al. [16], in addition to recording instrument failure or deformation and changes in working length (WL). Statistical analysis was done using Fisher exact test for instrument deformation and aberrations and Mann Whitney test for width measurements. Significance was set at $\mathrm{P}<$ 0.05 .

\section{RESULTS}

None of the used rotary files separated inside the canal however TF showed significant deformation after single use compared to K3 (20/20 files of size 25/0.08 and $16 / 20$ of size $25 / 0.06, \mathrm{P}<0.001)$. K3 files resulted in significant changes in the WL implying straightening of the canals in $100 \%$ of the canals, compared to $30 \%$ in the TF group.

Generally more aberrations were found in canals prepared with K3 than TF including ledges, perforation and creating danger zones, however statistical significance was reached only in the incidence of zipping and elbow formation $\mathrm{P}=0.04$. Table 1 summarizes the incidence of aberrations in the two files systems, when used up to an apical size of 25/06 and 30/06. Width measurements for the two systems are presented in Table 2; after preparation with size 30/06 the incidence of danger zone increased in both systems. However it was significantly greater in $\mathrm{K} 3$ system as it tends to remove more material from the inner aspect of the curve at many levels $(1,2,3)$ after preparation with size $30 / 06(\mathrm{P}=0.001, \mathrm{P}=0.003, \mathrm{P}$ $=0.007$ ) implying creating a danger zone, in addition to outer widening (transportation) at the apical end after size 30/06 ( $\mathrm{P}<0.001)$.

Whereas TF created a danger zone at the apex of second curve after preparation with 25/06 and 30/06 (P = $0.003)$.

\section{DISCUSSION}

Understanding material properties and its impact on instrument performance is crucial for the clinician. Recently thermomechanical treatment and alteration in the manufacturing process has been attempted to improve

Table 1. Incidence of aberrations after final apical preparation with size 25/0.06 and 30/0.06 using TF and K3 systems.

\begin{tabular}{|c|c|c|}
\hline & $\mathrm{TF}(\mathrm{n}=20) \%$ & $\mathrm{~K} 3(\mathrm{n}=20) \%$ \\
\hline \multicolumn{3}{|c|}{ Aberration after preparation with file size $25 / 0.06$} \\
\hline Ledges & 0 & 10 \\
\hline Zipping & 0 & $40^{*}$ \\
\hline Elbow & 0 & $40^{*}$ \\
\hline Outer widening in first curve & 0 & 0 \\
\hline Outer widening in $2^{\text {nd }}$ curve & 0 & 0 \\
\hline Danger zone in first curve & 50 & 90 \\
\hline Danger zone in second curve & 80 & 100 \\
\hline Perforation & 0 & 10 \\
\hline \multicolumn{3}{|c|}{ Aberration after preparation with file size 30/0.06 } \\
\hline Ledges & 20 & 50 \\
\hline Zipping & 20 & 50 \\
\hline Elbow & 20 & 40 \\
\hline Outer widening in first curve & 10 & 0 \\
\hline Outer widening in $2^{\text {nd }}$ curve & 0 & 0 \\
\hline Danger zone in first curve & 70 & 100 \\
\hline Danger zone in second curve & 90 & 100 \\
\hline Perforation & 0 & 0 \\
\hline
\end{tabular}


Table 2. Mean width measurements (mm) after preparation with TF and K3 systems.

\begin{tabular}{|c|c|c|c|c|c|c|}
\hline \multirow[t]{2}{*}{ Width measurement } & \multicolumn{2}{|c|}{ Total } & \multicolumn{2}{|c|}{ Inner } & \multicolumn{2}{|c|}{ Outer } \\
\hline & $\begin{array}{c}\text { TF } \\
\mathrm{M} \pm \mathrm{SD}\end{array}$ & $\begin{array}{c}\mathbf{K 3} \\
\mathrm{M} \pm \mathrm{SD} \\
\end{array}$ & $\begin{array}{c}\text { TF } \\
M \pm S D\end{array}$ & $\begin{array}{c}\mathbf{K 3} \\
\mathrm{M} \pm \mathrm{SD} \\
\end{array}$ & $\begin{array}{c}\mathbf{T F} \\
\mathrm{M} \pm \mathrm{SD}\end{array}$ & $\begin{array}{c}\mathbf{K 3} \\
\mathrm{M} \pm \mathrm{SD} \\
\end{array}$ \\
\hline \multicolumn{7}{|c|}{ Preparation ended with size 25/0.06 } \\
\hline Half way from orifice & $0.79 \pm 0.05$ & $0.72 \pm 0.03^{*}$ & $0.17 \pm 0.05$ & $0.20 \pm 0.02$ & $0.24 \pm 0.03$ & $0.22 \pm 0.03$ \\
\hline Beginning of $1^{\text {st }}$ curve & $0.62 \pm 0.04$ & $0.60 \pm 0.03$ & $0.21 \pm 0.05$ & $0.23 \pm 0.04$ & $0.14 \pm 0.04$ & $0.12 \pm 0.02$ \\
\hline Apex of 1 st curve & $0.58 \pm 0.03$ & $0.57 \pm 0.02$ & $0.25 \pm 0.12$ & $0.24 \pm 0.03$ & $0.08 \pm 0.01$ & $0.08 \pm 0.03$ \\
\hline Apex of $2^{\text {nd }}$ curve & $0.33 \pm 0.03$ & $0.33 \pm 0.26$ & $0.11 \pm 0.26$ & $0.08 \pm 0.02^{*}$ & $0.07 \pm 0.06$ & $0.06 \pm 0.02$ \\
\hline Apical end & $0.26 \pm 0.05$ & $0.30 \pm 0.30$ & $0.02 \pm 0.02$ & $0.02 \pm 0.02$ & $0.07 \pm 0.04$ & $0.11 \pm 0.07$ \\
\hline \multicolumn{7}{|c|}{ Preparation ended with size 30/0.06 } \\
\hline Half way from orifice & $0.84 \pm 0.03$ & $0.81 \pm 0.03$ & $0.19 \pm 0.02$ & $0.25 \pm 0.02^{*}$ & $0.26 \pm 0.03$ & $0.32 \pm 0.21$ \\
\hline Beginning of $1^{\text {st }}$ curve & $0.69 \pm 0.02$ & $0.71 \pm 0.04$ & $0.27 \pm 0.04$ & $0.34 \pm 0.04^{*}$ & $0.14 \pm 0.02$ & $0.13 \pm 0.02$ \\
\hline Apex of 1st curve & $0.62 \pm 0.02$ & $0.67 \pm 0.05^{*}$ & $0.28 \pm 0.04$ & $0.35 \pm 0.04^{*}$ & $0.07 \pm 0.02$ & $0.08 \pm 0.02$ \\
\hline Apex of $2^{\text {nd }}$ curve & $0.35 \pm 0.04$ & $0.38 \pm 0.04$ & $0.13 \pm 0.03$ & $0.10 \pm 0.02^{*}$ & $0.06 \pm 0.02$ & $0.10 \pm 0.19$ \\
\hline Apical end & $0.31 \pm 0.05$ & $0.31 \pm 0.05$ & $0.03 \pm 0.00$ & $0.02 \pm 0.02$ & $0.12 \pm 0.07$ & $0.13 \pm 0.06^{*}$ \\
\hline
\end{tabular}

flexibility and fatigue resistance [17]. Studies evaluating the impact of this property on the shaping ability of files manufactured by this procedure are scarce, with variation in assessment criteria.

This study evaluated the shaping ability of TF, manufactured with R-phase, which has been shown to be superelastic with a different path of crack propagation compared to non electropolished ground files. [18] The results of this study are in accordance with previous findings regarding better shaping ability of TF $[8,9]$. However this is the first study to investigate shaping ability in S-shaped canals. El Batouty et al. have shown that TF resulted in the least change in the overall canal curvature compared to K3 system in distal root canals of mandibular teeth with 25 and 35 degrees curve [9].

The K3 system resulted in excessive resin removal from the inner aspect at multiple points which is a serious problem clinically that can result in strip perforation, in addition to apical transportation at the end of second curve which is in accordance with the findings of Gergi et al. [8], this could be attributed to the interaction of two aspects of the file systems; the cross sectional design and the taper of instrument used for apical preparation. On the other hand one study found $\mathrm{K} 3$ to be the best choice among 5 systems for preparation of S-shaped canals; this could be explained by the small taper and apical size used in that study $(25 / 0.04)$ and the variation in preparation sequence that included 8 files for every canal [19]. It is worth noting however that the design of $\mathrm{K} 3$ system has been updated by SybronEndo via the introduction of the thermomechanically treated $\mathrm{K} 3 \mathrm{XF}$, which is claimed to have better flexibility and fatigue resistance.

Although in previous studies TF were not found superior to Flexmaster files when used in 0.04 taper in terms of apical transportation [20], they demonstrated significantly lower incidence of transportation compared to the Protaper 0.08 taper when evaluated by computed tomography [8]. Considering the above findings and the fact that both FlexMaster and K3 files are manufactured by grinding process the authors concluded that the superiority of TF my not be attributed solely to the manufacturing process but rather to the taper and cross sectional design.

In this study potential contributing factors were standardized by matching the size and taper of the final apical file. Advantage of TF include creating less aberration than K3 implying more flexibility. However it is worth noting that it resulted in danger zone at the apex of second curve even after preparation with 25/0.06, which may be related to the complexity of the S-shaped curvature rather than suboptimum characteristics of the file system. Therefore to optimize shaping results it may be advantageous to use small taper in curved canals [21]. It is worth noting that when the apical size increased to 30 , both systems resulted in high incidence of danger zone $(70 \%-100 \%)$. Considering the fact that debridement is optimized by larger apical preparations [22], it may be wise to balance between the size and taper of instruments used in S-shaped canals.

Second advantage is that instruments made from the R-phase alloy including Twisted files are flexible, which allows a greater amount of deformation at a similar torque level than austenitic phase [17]. The significant deformation occurred in TF in this study may be a positive warning sign before fracture following multiple uses. However combined with the reported negative effects of multiple autoclave cycles it highlights the manufacturer recommendations of single use. [23] This may be advan- 
tageous in terms of infection control while dearer on the other hand.

However considering variation in material properties between dentine and resin, and the two dimensional assessment method employed, complete extrapolation of the results to the clinical practice may not be wise and validation of these results using three dimensional technologies in a clinical setup is required.

\section{CONCLUSION}

Within the limitation of this study, it can be concluded that twisted files manufactured by new technique can be used in preparation of S-Shaped root canals up to size 25/0.06.

\section{CLINICAL SIGNIFICANCE}

The flexibility of thermomechanically treated files is beneficial in preparing canals with multiple curvatures. However attention should be paid to the instrument taper and the final apical size of the preparation.

\section{ACKNOWLEDGEMENTS}

The authors deny any conflicts of interest. We affirm that we have no financial affiliation (e.g., employment, direct payment, stock holdings, retainers, consultantships, patent licensing arrangements or honoraria), or involvement with any commercial organization with direct financial interest in the subject or materials discussed in this manuscript, nor have any such arrangements existed in the past three years.

\section{REFERENCES}

[1] Schilder, H. (1974) Cleaning and shaping the root canal. Dental Clinics of North America, 18, 269-296.

[2] Wu, M.K., Fan, B. and Wesselink, P.R. (2000) Leakage along apical root fillings in curved root canals. Part I: Effects of apical transportation on seal of root fillings. Journal of Endodontics, 26, 210-216. http://dx.doi.org/10.1097/00004770-200004000-00003

[3] Tan, B.T. and Messer, H.H. (2002) The quality of apical canal preparation using hand and rotary instruments with specific criteria for enlargement based on initial apical file size. Journal of Endodontics, 28, 658-664. http://dx.doi.org/10.1097/00004770-200209000-00008

[4] Schafer, E, Schulz-Bongert, U. and Tulus, G. (2004) Comparison of hand stainless steel and nickel titanium rotary instrumentation: A clinical study. Journal of Endodontics, 30, 432-435.

http://dx.doi.org/10.1097/00004770-200406000-00014

[5] Glossen, C.R., Haller, R.H., Dove, S.B. and del Rio, C.E. (1995) A comparison of root canal preparations using Ni-Ti hand, Ni-Ti engine-driven, and K-Flex endodontic instruments. Journal of Endodontics, 21,146-151. http://dx.doi.org/10.1016/S0099-2399(06)80441-3

[6] Schafer, E. and Schlingemann, R. (2003) Efficiency of rotary nickel-titanium K3 instruments compared with stainless steel hand K-Flexofile. Part 2. Cleaning effectiveness and shaping ability in severely served root canals of extracted teeth. International Endodontic Journal, 36, 208-217.

http://dx.doi.org/10.1046/j.1365-2591.2003.00644.x

[7] Gambarini, G., Grande, N.M., Plotino, G., Somma, F., Garala, M, De Luca, M., et al. (2008) Fatigue resistance of engine-driven rotary nickel-titanium instruments produced by new manufacturing method. Journal of Endodontics, 34, 1003-1005.

http://dx.doi.org/10.1016/i.joen.2008.05.007

[8] Gergi, R., Rjeily, J.A., Sader, J. and Naaman, A. (2010) Comparison of canal transportation and centering ability of twisted files, Pathfile-ProTaper system, and stainless steel hand K-files by using computed tomography. Journal of Endodontics, 36, 904-907.

http://dx.doi.org/10.1016/j.joen.2009.12.038

[9] El Batouty, K.M. and Elmallah, W.E. (2011) Comparison of canal transportation and changes in canal curvature of two nickel-titanium rotary instruments. Journal of Endodontics, 37, 1290-1292. http://dx.doi.org/10.1016/j.joen.2011.05.024

[10] Guttmaan, J.L. (1997) Problem solving in endodontics. 3rd Edition, Mosby-Year book Inc., Missouri, 116.

[11] Bonaccorso, A., Cantatore, G., Condorelli, G.G., Schafer, E. and Tripi, T.R. (2009) Shaping ability of four nickeltitanium rotary instruments in simulated S-shaped canals. Journal of Endodontics, 35, 883-886.

[12] Burroughs, J.R., Bergeron, B.E., Roberts, M.D., Hagan, J.L. and Himel, V.T. (2012) Shaping ability of three nickel-titanium endodontic file systems in simulated S-shaped root canals. Journal of Endodontics, 38, 1618-1621. http://dx.doi.org/10.1016/j.joen.2012.09.011

[13] Bryant, S.T., Thompson, S.A., al-Omari, M.A. and Dummer, P.M. (1998) Shaping ability of ProFile rotary nickel-titanium instruments with ISO sized tips in simulated root canals: Part 2. International Endodontic Journal, 31, 282-289. http://dx.doi.org/10.1046/j.1365-2591.1998.00150.x

[14] Rangel, S, Cremonese, R., Bryant, S. and Dummer, P. (2005) Shaping ability of RaCe rotary nickel-titanium instruments in simulated root canals. Journal of Endodontics, 31, 460-463. http://dx.doi.org/10.1097/01.don.0000148144.79173.aa

[15] Yoshimine, Y., Ono, M. and Akamine, A. (2005) The shaping effects of three nickel-titanium rotary instruments in simulated S-shaped canals. Journal of Endodontics, 31, 373-375.

http://dx.doi.org/10.1097/01.don.0000140568.40462.43

[16] Al-Omari, M.A., Dummer, P.M. and Newcombe, R.G. (1992) Comparison of six files to prepare simulated root canals. International Endodontic Journal, 25, 57-66. http://dx.doi.org/10.1111/j.1365-2591.1992.tb00738.x

[17] Shen, Y., Zhou, H.M., Zheng, Y.F., Peng, B. and Haapasalo, M. (2013) Current challenges and concepts of the thermomechanical treatment of nickel-titanium instruments. Journal of Endodontics, 39, 163-172. http://dx.doi.org/10.1016/j.joen.2012.11.005 
[18] Kim, H.C., Yum, J., Hur, B. and Cheung, G.S. (2009) Cyclic fatigue and fracture characteristics of ground and twisted nickel-titanium rotary files. Journal of Endodontics, 36, 147-152.

http://dx.doi.org/10.1016/j.joen.2009.09.037

[19] Ersev, H., Yilmaz, B., Ciftcioglu, E. and Ozkarsli, S.F. (2010) A comparison of the shaping effects of 5 nickeltitanium rotary instruments in simulated S-shaped canals. Oral Surgery Oral Medicine Oral Pathology Oral Radiology and Endodontics, 109, e86-93. http://dx.doi.org/10.1016/j.tripleo.2009.12.033

[20] Duran-Sindreu, F., Garcia, M., Olivieri, J.G., Mercade, M., Morello, S. and Roig, M. (2012) A comparison of apical transportation between FlexMaster and Twisted Files rotary instruments. Journal of Endodontics, 38, 993995. http://dx.doi.org/10.1016/j.joen.2012.03.019
[21] Schafer, E., Dzepina, A. and Danesh, G. (2003) Bending properties of rotary nickel-titanium instruments. Oral Surgery Oral Medicine Oral Pathology Oral Radiology and Endodontics, 96, 757-763.

http://dx.doi.org/10.1016/S1079-2104(03)00358-5

[22] Card, S.J., Sigurdsson, A, Orstavik, D. and Trope, M. (2002) The effectiveness of increased apical enlargement in reducing intracanal bacteria. Journal of Endodontics, 28, 779-783.

http://dx.doi.org/10.1097/00004770-200211000-00008

[23] Hilfer, P.B., Bergeron, B.E., Mayerchak, M.J., Roberts, H.W. and Jeansonne B.G. (2010) Multiple autoclave cycle effects on cyclic fatigue of nickel-titanium rotary files produced by new manufacturing methods. Journal of Endodontics, 37, 72-74. http://dx.doi.org/10.1016/j.joen.2010.09.011 